Article

\title{
Dual-Sensitive Gold-Nanocubes Platform with Synergistic Immunotherapy for Inducing Immune Cycle Using NIR-Mediated PTT/NO/IDO
}

\author{
Hsin-Yi Tsao ${ }^{1,+}$, Hung-Wei Cheng ${ }^{1,+}$, Chia-Chi Kuo ${ }^{1}$ and San-Yuan Chen ${ }^{1,2,3,4, *}$ \\ 1 Materials Science and Engineering, National Yang Ming Chiao Tung University, Hsinchu 300, Taiwan; \\ yvonne880217@gmail.com (H.-Y.T.); mlb14756@gmail.com (H.-W.C.); d42172000@gmail.com (C.-C.K.) \\ 2 Graduate Institute of Biomedical Science, China Medical University, Taichung 404, Taiwan \\ 3 Frontier Research Centre on Fundamental and Applied Sciences of Matters, National Tsing Hua University, \\ Hsinchu 300, Taiwan \\ 4 School of Dentistry, College of Dental Medicine, Kaohsiung Medical University, Kaohsiung 807378, Taiwan \\ * Correspondence: sanyuanchen@nycu.edu.tw \\ + These authors contributed equally to this work.
}

check for updates

Citation: Tsao, H.-Y.; Cheng, H.-W.; Kuo, C.-C.; Chen, S.-Y. Dual-Sensitive Gold-Nanocubes Platform with Synergistic Immunotherapy for Inducing Immune Cycle Using NIR-Mediated PTT/NO/IDO.

Pharmaceuticals 2022, 15, 138.

https://doi.org/10.3390/

ph15020138

Academic Editor: Chi-Jen Shih

Received: 29 December 2021

Accepted: 23 January 2022

Published: 25 January 2022

Publisher's Note: MDPI stays neutral with regard to jurisdictional claims in published maps and institutional affiliations.

Copyright: () 2022 by the authors Licensee MDPI, Basel, Switzerland. This article is an open access article distributed under the terms and conditions of the Creative Commons Attribution (CC BY) license (https:// creativecommons.org/licenses/by/ $4.0 /)$.

\begin{abstract}
Currently, the combination therapies based on immunotherapy have been rapidly developed, but the response rate has not always increased as expected. Nano-platform has become a potential strategy which can trigger multi-functions to increase immunotherapeutic efficacy via activating T-cells and photothermal effect. Herein, to avoid the self-degradation and provide $\mathrm{pH}$-sensitive property, S-nitrosoglutathione (GSNO) was loaded in gold nanocubes (AuNCs) with polyacrylic acid (PAA) coating. Subsequently, the layer-by-layer (LbL) assembly of iron oxide nanoparticles $\left(\mathrm{Fe}_{3} \mathrm{O}_{4}\right)$ and betanin can provide the conjugation of 1-methyl-D-tryptophan (1-M-DT) on the nanoparticle to form an NO gas-photothermal-immune nano-platform (GAPFBD) for achieving combinatory therapy of NO gas, photothermal therapy (PTT), and indoleamine 2,3-dioxygenase (IDO) immunotherapy. After irradiation by 808-nm laser, the GSNO was released under a lower $\mathrm{pH}$ environment due to the structural transformation of PAA and then transformed into NO production of $64.5 \pm 1.6 \%$ under PTT. The combination of PTT and NO gas therapy can effectively eliminate cancer cells, resulting in a large amount of tumor-associated antigens (TAAs) compared to the individual treatment in vitro. Additionally, the released 1-M-DT inhibited IDO and combined with TAAs to enhance maturation of dendritic cells (DCs), indicating the excellent synergistic effect of PTT and NO with IDO inhibitors. These results revealed that this dual-sensitive nanoparticle presented a combination strategy of $\mathrm{PTT} / \mathrm{NO} / \mathrm{IDO}$ for the synergistic effect to promote DC maturation.
\end{abstract}

Keywords: S-nitrosoglutathione (GSNO); gold nanocubes (AuNCs); photothermal therapy (PTT); IDO immunotherapy

\section{Introduction}

With the advancement and development of nanomedicine, different innovative technologies such as gene therapy, photothermal therapy (PTT), photodynamic therapy (PDT), and immunotherapy have been gradually applied to various cancer treatments. In recent years, combination therapies based on the use of various types of immune modulators have been developed, including indoleamine 2,3-dioxygenase (IDO) immunotherapy [1], CAR-T [2], immune checkpoint [3], and. Among them, IDO inhibitors can inhibit the degradation of tryptophan (Trp) and activate T cells to produce an immune response through regulating the balance of Trp and kynurenine (Kyn) [1,4]. However, IDO inhibitors are not able to induce effective in vivo IDO inhibition due to their low in vitro potency and the similar plasma concentrations of the IDO substrate [5]. To solve this problem, recent studies have demonstrated that the use of the nano-platform to deliver the IDO inhibitors can 
significantly enhance the therapeutic effect. For instance, Chen et al. used a nanoplatform to deliver the IDO inhibitor NLG919 and paclitaxel, indicating that the combination treatment presented better tumor suppression than the single treatment group [6]. In addition, Xing et al. also proved that this combination using photodynamic therapy (PDT) and IDO inhibitor can produce an apparent effect on long-term immune memory [7]. The abovementioned studies indicated that the use of nano-formulated IDO inhibitors combined with other therapies has great potential for achieving efficacious therapies. However, PDT is usually limited by the strong demand for oxygen, resulting in ineffectively treating the hypoxic area of the tumor.

Currently, nitric oxide (NO), a common biological signal molecule in organisms, has several tumoricidal effects, such as inhibiting DNA synthesis, activating caspase protein, and promoting cell apoptosis [8-10]. The destruction of cancer cells by NO is gradually regarded as an alternative to the current research on PDT to treat cancer. At the same time, NO contains free radicals, which are a member of highly reactive nitrogen species (RNS) and can regulate a variety of cancer-related reactions in tumor tissues [11]. In addition, $\mathrm{NO}$ is also an important bioactive molecule exerting multiple functions in many physiological and pathological processes, including the ability to functionally inhibit the activity of IDO [8,12]. NO has been proven to promote cell apoptosis to reach the anti-tumor effects at high concentrations $[9,10]$. More importantly, NO can enhance the sensitivity of chemotherapy and irradiation therapy and further reconstruct the blood vessel to improve the recruitment of immune cells [11]. Nonetheless, the extremely short half-life of NO seriously limits its therapeutic effect [13], and high reactive NO can cause cell death and tissue damage for normal cells due to exposure to high concentrations of NO [14]. Recently, NO donors have been developed for decreasing the toxicity of NO in the use of NO gas therapy. For example, S-nitrosoglutathione (GSNO) [15] is one of the NO donors which has been used in various nano-platforms to increase the effective accumulation in targeted tissues and tumors [16]. Additionally, GSNO is an endogenous species that can be decomposed into NO gases and glutathione disulphide (GSSG) by heat and UV/visible light. After the reaction is triggered, the generated NO can react with reactive oxygen species (ROS) to produce RNS, which boosts the destructive activity and enhances the overall damage $[17,18]$. Therefore, various thermal-response nano-platforms have been designed for loading GSNO to release NO gases at an accurate time. For example, Zhang et al. developed the upconversion nanoparticles (UCNPs) combined with photosensitive NO donors to modify its structure and release NO [19]. However, the UCNPs with low drug-loading and low energy-conversion efficiency greatly limits the application and development of this system.

Gold nanocubes (AuNCs) are a photothermal conversion nano-material [20,21] that have been widely used as the agent of PTT to induce the ablation of the targeted tissue. AuNCs can also be a promising nano-platform for GSNO because they can absorb specific irradiation wavelengths for generating heat to induce the production of NO gas. In addition, NO gas can fundamentally overcome the challenge of the production of heat shock proteins under thermal stimulation after PTT [22]. Hence, in this study, we developed a dual-sensitive nano-platform using AuNCs to load GSNO and combine with inhibitory properties of IDO to increase the synergistic effect for achieving the combination therapy. During the synthesis of the dual-sensitive nanoparticle, GSNO-loaded AuNCs were first encapsulated within polyacrylic acid (PAA), followed by coating iron oxide nanoparticles $\left(\mathrm{Fe}_{3} \mathrm{O}_{4}\right)$, betanin, and 1-methyl-D-tryptophan (1-M-DT) through layer-by-layer assembly to build up a NO gas-photothermal-immune nano-platform in Scheme 1a. GSNO was triggered by the PTT for the production of NO gas. PAA is a pH-sensitive polymer coated on the surface of AuNCs through the anion of PAA and the cation of AuNCs [5,23]. It can not only protect GSNO from leaking but also control the accurate release location. $\mathrm{Fe}_{3} \mathrm{O}_{4}$ as magnetic navigation can deliver the nanoparticle to the tumor site. Betanin is a watersoluble red beet extract that can be degraded under high temperatures [24] to promote the release of 1-M-DT. The treatment mechanism of the NO gas-photothermal-immune 
nanoplatform was illustrated in Scheme 1b. First, GSNO can be released from the GAPFBD at the intracellular level due to the structural transformation of PAA at $\mathrm{pH}=5.0$. Then, the dual-sensitive nanoparticle can simultaneously initiate multiple treat mechanisms triggered by 808-nm laser irradiation to achieve the synergistic effects. Under 808-nm laser irradiation, the photothermal effect was induced by GAPFBD to generate heat for accelerating the dissolution of GSNO into NO gas. The heat can also trigger the release of 1-M-DT to suppress the degradation of Trp into Kyn. Finally, tumor-associated antigens (TAAs) can be induced to enhance the maturation of dendritic cells (DCs), causing the activation of T cells. This demonstrates that the GAPFBD has great potential multi-functions to promote the maturation of dendritic cells (DCs) for achieving long-term immunity to enhance tumor treatment.

(a)

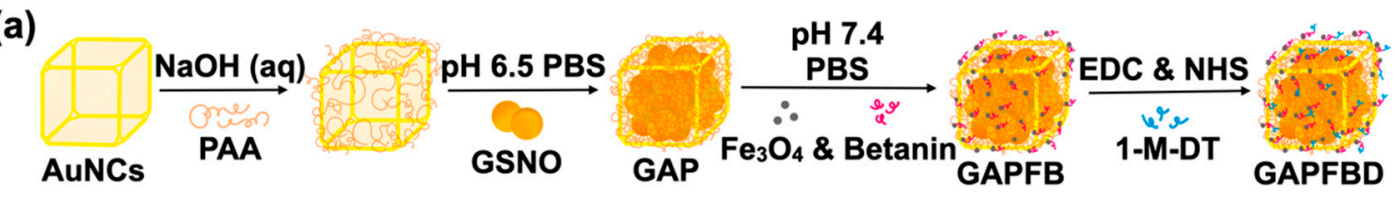

(b)

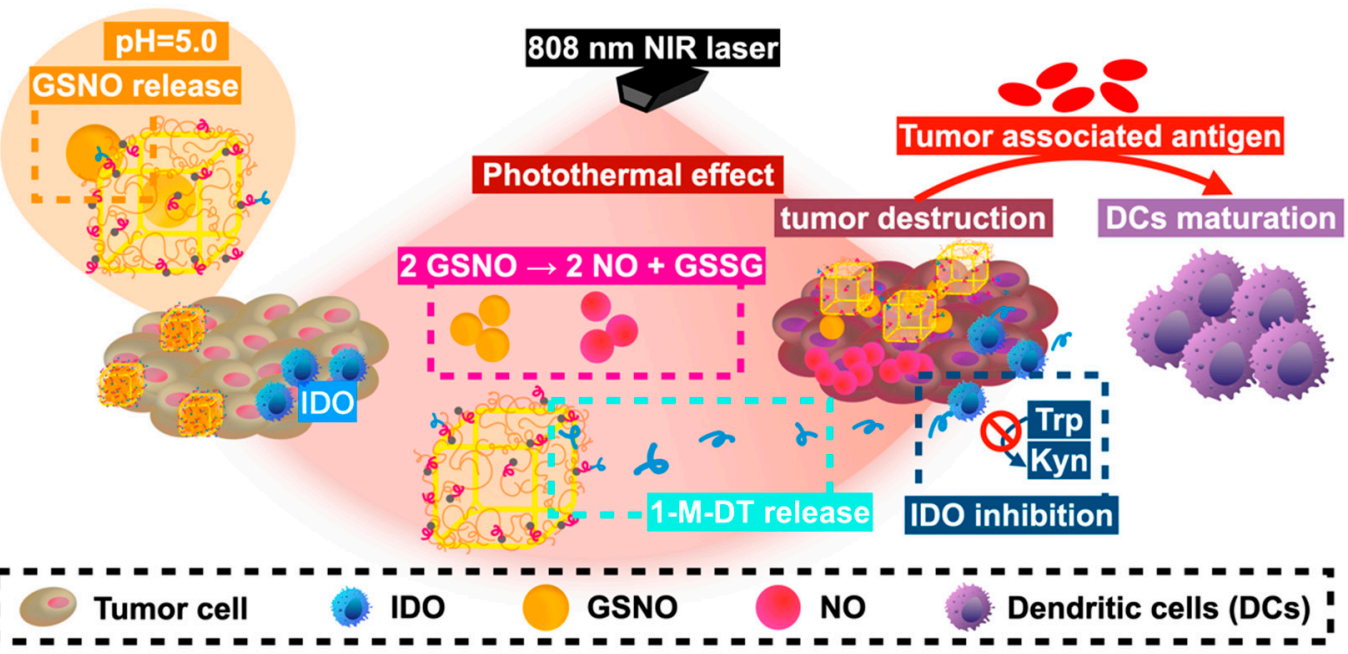

Scheme 1. Schematic illustration of (a) the synthesis of GSNO-AuNCs-Fe $\mathrm{O}_{4}$-betanin-1-M-DT (GAPFBD) nanoparticle and (b) the synergistic mechanisms of GAPFBD in tumor treatment.

\section{Results and Discussion}

\subsection{Characterization of GSNO-AuNCs-PAA-Fe ${ }_{3} \mathrm{O}_{4}$-Betanin-1-M-DT (GAPFBD)}

The synthesis and characterization of the GSNO-AuNCs-PAA-Fe $\mathrm{O}_{4}$-betanin-1-MDT (GAPFBD) were first analyzed. The GSNO was loaded in AuNCs by controlling the $\mathrm{pH}$, and subsequently, GSNO-loaded AuNCs were encapsulated within polyacrylic acid (PAA) to form GSNO-AuNCs-PAA(GAP) through the anion of PAA with the metal cation under alkaline conditions. Next, the iron oxide $\left(\mathrm{Fe}_{3} \mathrm{O}_{4}\right)$ and betanin were coated on the surface of GAP sequentially through the layer-by-layer technique to form composite GSNO-AuNCs-PAA-Fe $\mathrm{O}_{4}$-betanin (GAPFB). Finally, the 1-methyl-D-tryptophan (1-MDT) was grafted to the GAPFB via EDC/NHS reaction to form the GAPFBD. During the synthesis of GAPFBD, the particle size, zeta potential, and morphology of AuNC-based nanoparticles were further analyzed. As shown in Figure 1a, the particle sizes measured by dynamic light scattering (DLS) increased gradually from $92.5 \pm 13.9 \mathrm{~nm}$ of AuNCs, $123.3 \pm 15.4 \mathrm{~nm}$ of GAP, $146.5 \pm 3.7 \mathrm{~nm}$ of GAPFB to $179.7 \pm 23.4 \mathrm{~nm}$ of GAPFBD. Further, to ensure that the nanoparticle can be fabricated via layer-by-layer processing, the zeta potential of GAP, GAPF, GAPFB, and GAPFBD was measured as $-64.73 \mathrm{mV},+9.55 \mathrm{mV}$, $-49.33 \mathrm{mV}$, and $+30.31 \mathrm{mV}$ in Figure $1 \mathrm{~b}$, respectively. The results confirmed that the GSNO-AuNCs-PAA-Fe $\mathrm{O}_{4}$-betanin-1-M-DT (GAPFBD) nanoparticle can be successfully synthesized using AuNCs through the layer-by-layer assembly. Moreover, the morphology and dispersion of the AuNCs can be observed by SEM and TEM as shown in Figure 1c,e, 
respectively, illustrating that AuNCs presented the square shapes. The SEM and TEM of GAPFBD in Figure $1 \mathrm{~d}, \mathrm{f}$ indicated the AuNCs were coated with multiple-layers to form a complex structure. The $\mathrm{Fe}_{3} \mathrm{O}_{4}$ coating on the GAP can be confirmed using TEM imaging and energy-dispersive X-ray spectroscopy (EDS), as shown in Figure S1. The atomic percentage of Fe and Au was measured as 5.48\% and $85.38 \%$ in Table S1. Furthermore, the encapsulation efficiency of GSNO was $74.42 \pm 4.14 \%$ and the conjugating ratio of 1-M-DT was $74.00 \pm 1.41 \%$ based on the standard curve in Figure S2, respectively. The stability of GAPFBD was also conducted by placing the sample in $\mathrm{pH}=7.4$ and $\mathrm{pH}=6.0 \mathrm{PBS}$ storage conditions in Figure S3.

(a)

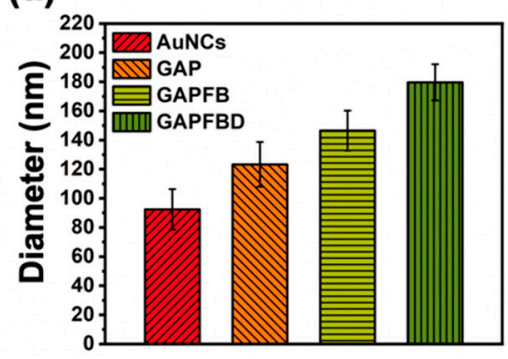

(b)

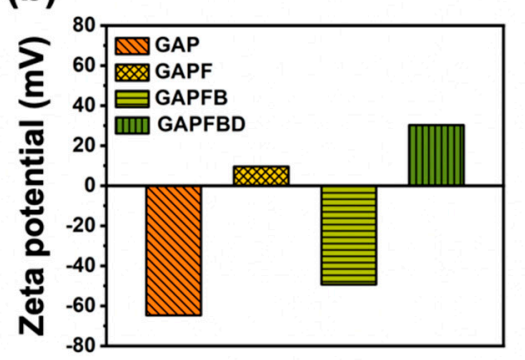

(c)

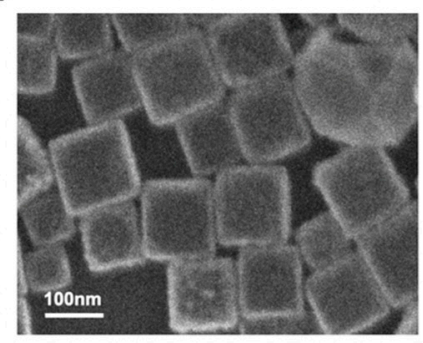

(d)

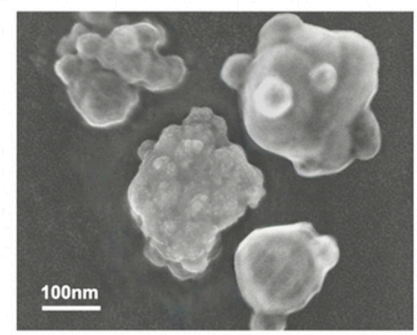

(e)

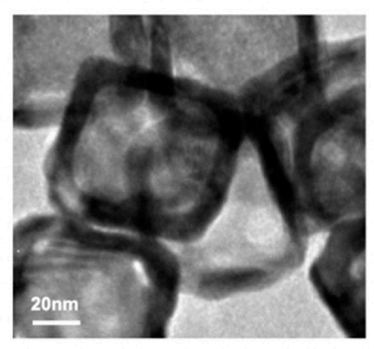

(f)

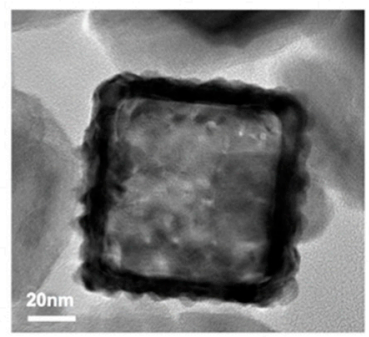

Figure 1. Characteristics of GAPFBD. (a) DLS of AuNCs, GAP, GAPFB and GAPFBD. (b) Zeta potential of GAP, GAPF, GAPFB, and GAPFBD. SEM image of (c) AuNCs and (d) GAPFBD. TEM image of (e) AuNCs and (f) GAPFBD.

\subsection{Thermally Dependent NO Production and $p H$-Responsive Drug Release}

The photothermal effect of GAPFB depends on the absorption of incident photons of AuNCs that convert photon energy into heat through optical excitation [25]. To evaluate the photothermal effect of GAPFB, the temperature curve of water, AuNCs, GAPFB, and GAPFBD was measured under NIR laser irradiation $\left(808 \mathrm{~nm}, 0.5 \mathrm{~W} / \mathrm{cm}^{2}\right)$ for $15 \mathrm{~min}$ in Figure 2a. The starting temperature was set at $37^{\circ} \mathrm{C}$ to imitate the body temperature. Without AuNCs, the temperature of water changed slightly from $37^{\circ} \mathrm{C}$ to $38^{\circ} \mathrm{C}$. In contrast, AuNCs presented an apparent change in the temperature from $37^{\circ} \mathrm{C}$ to $69{ }^{\circ} \mathrm{C}$ in $10 \mathrm{~min}$, while the temperature change in GAPFB was measured from $37^{\circ} \mathrm{C}$ to $53^{\circ} \mathrm{C}$, lower than AuNCs. The maximum temperature difference of AuNCs and GAPFBD was attributed to the multi-layer coating on AuNCs to reduce the thermal effect of GAPFBD. Here, it was noted that the GAPFBD can reach $45^{\circ} \mathrm{C}$ within $2 \mathrm{~min}$, indicating that GAPFBD still presented a better photothermal effect $[26,27]$. In addition, the temperature elevation after three cycles of NIR irradiation did not decrease in Figure 2b, indicating that GAPFBD possessed excellent photothermic stability, which was beneficial to perform repeated photothermal therapy in long-term clinical treatments. 
(a)

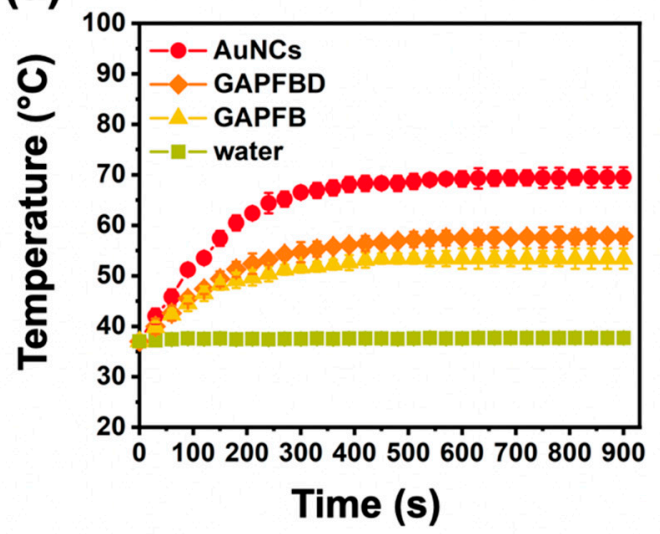

(b)

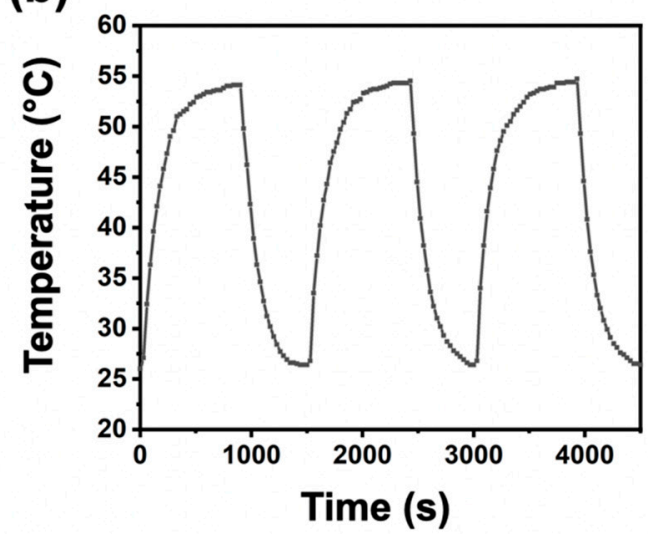

Figure 2. Photothermal effect of AuNC-based nanoparticles. (a) Heating curve of various nanoparticles under NIR starting from $37^{\circ} \mathrm{C}$ and (b) Photothermal cycling stability of GAPFBD over three on/off cycles of NIR laser irradiation.

To prove that GSNO-AuNCs-PAA- $\mathrm{Fe}_{3} \mathrm{O}_{4}$-betanin (GAPFB) can control GSNO to produce NO gas, an NIR laser was applied to raise the temperature [28]. Figure 3a shows the NO production of GSNO and GAPFB with/without NIR laser irradiation $\left(0.5 \mathrm{~W} / \mathrm{cm}^{2}\right.$, $10 \mathrm{~min}$ ) as measured by Nitric Oxide Assay Kit and calculated by the standard curve in Figure $\mathrm{S} 4$. GSNO produced $32.4 \pm 1.6 \%$ of NO due to the self-degradation of GSNO. As GSNO was irradiated with NIR laser, $35.8 \pm 1.97 \%$ NO was generated, indicating NIR laser displayed little effect on the generation of NO. In contrast, GAPFB produced a lower NO of $22.9 \pm 0.6 \%$ than GSNO, which was attributed to the fact that GSNO was well encapsulated in the GAPFB. However, with NIR laser treatment, the GAPFB produced a much higher NO of $64.5 \pm 1.6 \%$. The results confirmed that the conversion from GSNO into NO gas can be well triggered by GAPFB under NIR irradiation. In addition, to confirm that GAPFB can control the release of GSNO through PAA, the GSNO release was performed at various times of $1,2,4,8,12,24,48$, and $72 \mathrm{~h}$ under different $\mathrm{pH}$ values, including systemic circulation $(\mathrm{pH}=7.4)$, tumor microenvironment $(\mathrm{pH}=6.5)$, and intracellular $(\mathrm{pH}=5)$ in Figure $3 \mathrm{~b}$. GSNO released $19.8 \pm 3.0 \%$ at $\mathrm{pH}=7.4 \mathrm{in} 72 \mathrm{~h}$, indicating that GSNO was effectively encapsulated. In contrast, GSNO was compatibly released as $60.5 \pm 2.5 \%$ at $\mathrm{pH}=6.5$ and $87.6 \pm 2.0 \%$ at intracellular $\mathrm{pH}=5.0$, respectively, because the structure of PAA was opened at a lower $\mathrm{pH}$ value. The results demonstrated the increased release of GSNO under a lower $\mathrm{pH}$ condition. Moreover, in order to confirm that GAPFBD can release 1-M-DT in intracellular and tumor microenvironments, GAPFBD was separately placed at $\mathrm{pH}=7.4,6.5$, and 5.0, with/without NIR laser treatments in Figure 3c. The released amount of 1-M-DT was measured at about $23.8 \pm 4.5 \%$ at $\mathrm{pH}=7.4,56.7 \pm 4.4 \%$ at $\mathrm{pH}=6.5$, and $53.2 \pm 4.3 \%$ at $\mathrm{pH}=5.0 \mathrm{in} 72 \mathrm{~h}$. In addition, as NIR laser irradiation was applied at the time point of $24 \mathrm{~h}$ for $10 \mathrm{~min}$ at $\mathrm{pH}=5.0$ and $\mathrm{pH}=6.5$, it can be observed that the released amount of 1-M-DT was apparently increased by about $15 \%$ and finally reached $73.0 \pm 4.1 \%$ and $79.4 \pm 4.5 \%$ after $72 \mathrm{~h}$, respectively. The results demonstrated that the release of 1-M-DT from the GAPFBD can be controlled by NIR laser irradiation under different $\mathrm{pH}$ environments.

\subsection{Cellular Uptake}

To ensure the optimal time point of the maximum GSNO release under the NIR treatment, the intracellular uptake of GAPFB was observed at various incubation times. The nuclei and cytoskeleton of the Hep55.1c were stained by DAPI (blue) and rhodamine phalloidin (red), respectively. As shown in Figure 4a, GAPFB, as indicated in green, appeared around the cell at $4 \mathrm{~h}$ compared to $1 \mathrm{~h}$. Moreover, the intensity of green fluorescence presented an obvious increase within nuclei in $12 \mathrm{~h}$ and $24 \mathrm{~h}$. The endocytosis behavior can be further confirmed using flow cytometry in Figure $4 b, c$. The mean fluorescent intensity 
(MFI) of the cell relative to GAPFB was observed after $1 \mathrm{~h}$ and increased with the incubation time. The maximum cellular uptake amount of the GAPFB appeared at $24 \mathrm{~h}$ so that it was selected for subsequent cell experiments.

(a)

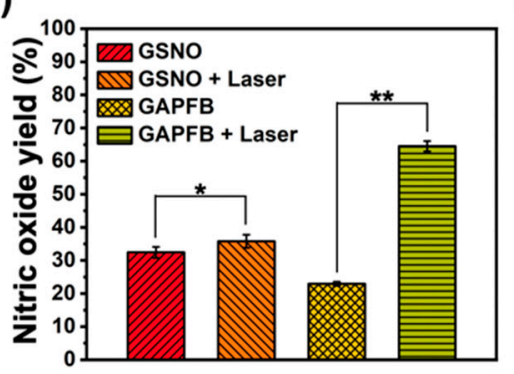

(b)

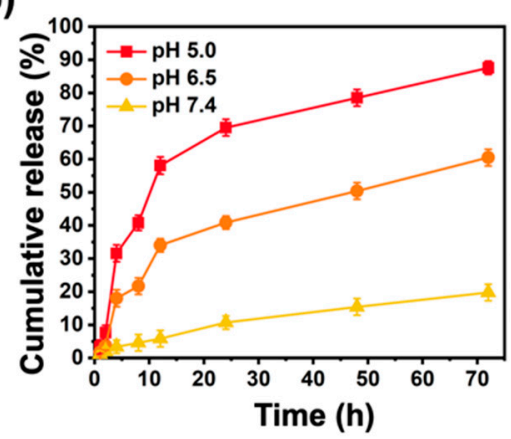

(c)

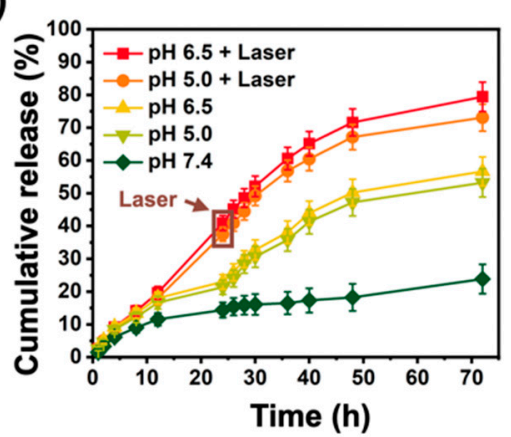

Figure 3. (a) NO production with/without NIR laser. (b) GSNO release under different $\mathrm{pH}$ conditions. (c) 1-M-DT release under different $\mathrm{pH}$ conditions with/without NIR laser. Data are expressed as mean $\pm \mathrm{SD}, n=3$. Two-tailed Student's test was used. ${ }^{*} p<0.05,{ }^{* *} p<0.01$.

(a)

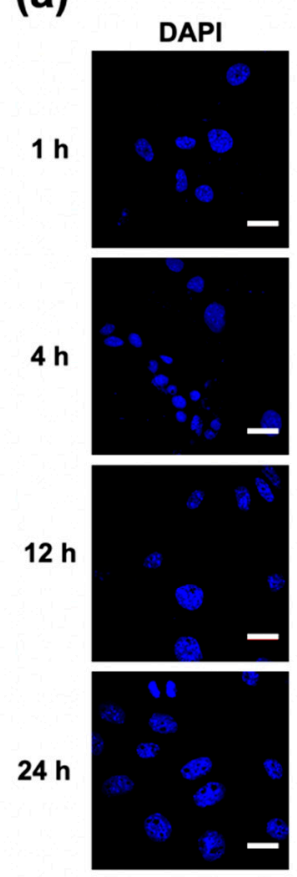

Alexa Fluor
488
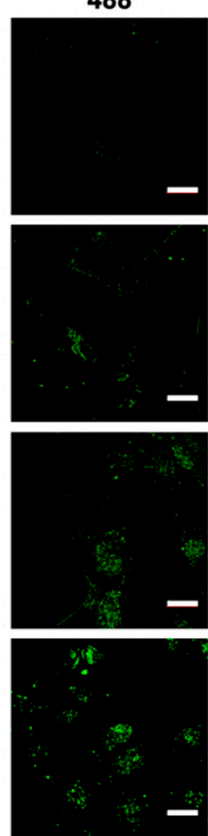

Rhodamine
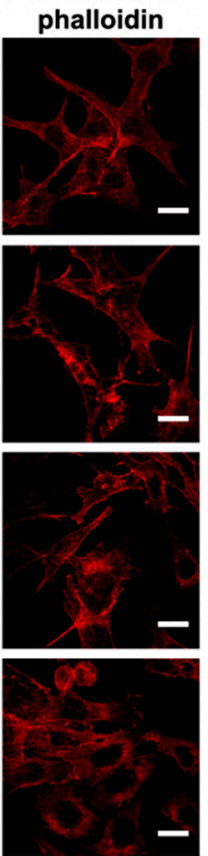
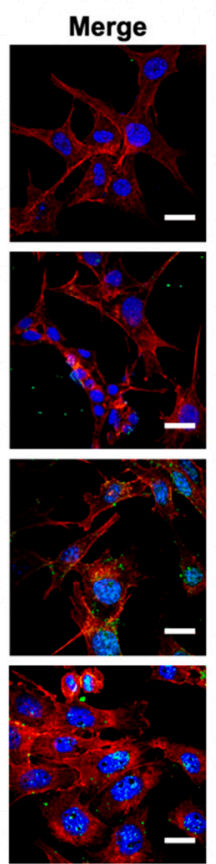

(b)

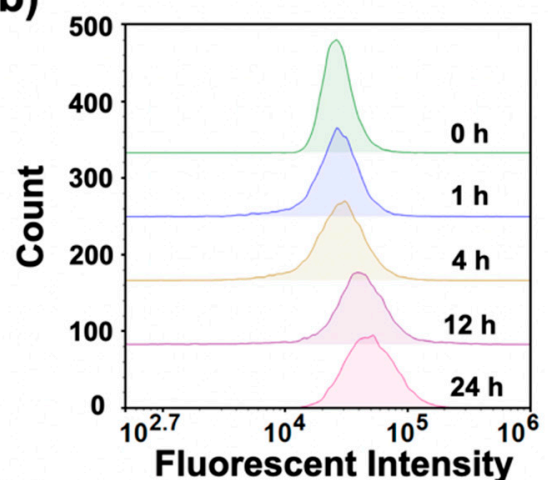

(c)

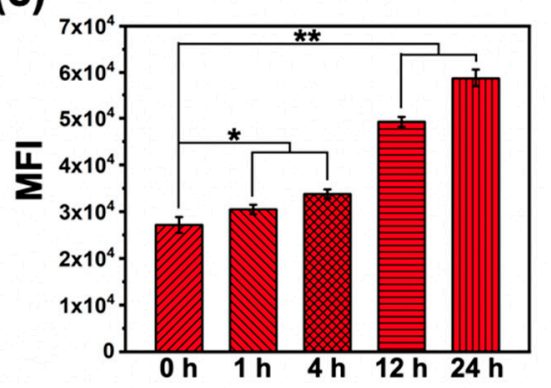

Figure 4. Cellular uptake of GAPFB. (a) Fluorescence microscopy image. DAPI (blue) and rhodamine phalloidin (red) were used for staining the nuclei and cytoskeleton, respectively. Green indicated GAPFB. (Scale bar $=100 \mu \mathrm{m})(\mathbf{b})$ Flow cytometric analysis and (c) quantified results. Data are expressed as mean $\pm \mathrm{SD}, n=3$. Two-tailed Student's test was used. ${ }^{*} p<0.05,{ }^{* *} p<0.01$.

\subsection{In Vitro NO/Photothermal Treatment and Apoptosis Analysis}

In order to investigate the cytotoxicity of GAPFB, Hep55.1c cells were incubated with different concentrations $(25,50$, and $100 \mu \mathrm{g} / \mathrm{mL})$ of AuNCs and GAPFB for $24 \mathrm{~h}$. As shown in Figure 5a, the AuNC group showed negligible cytotoxicity even under a higher concentration of $100 \mu \mathrm{g} / \mathrm{mL}$. As the cells were incubated with GAPFB, it was found that the cell viability presented a slight decrease when increasing the GAPFB amount, which may be attributed to self-degradation of GSNO because of a higher concentration of GSNO in the GAPFB group with $100 \mu \mathrm{g} / \mathrm{mL}$. Therefore, $50 \mu \mathrm{g} / \mathrm{mL}$ was used in the following ex- 
periments. Furthermore, to explore the PTT/NO combination treatment on the cell viability of Hep55.1c cells, GSNO, APFB, and GAPFB in the absence/presence of NIR laser were conducted. Figure $5 b$ showed the cell viability of Hep55.1c cells treated in GSNO, APFB, and GAPFB without NIR light irradiation as $85.4 \pm 3.4 \%, 84.3 \pm 3.0 \%$, and $83.5 \pm 4.4 \%$, respectively. The result illustrated that the groups showed no obvious differences in cell viability and maintained the cell survival rates around $80 \%$. However, the cell viability in the GSNO-treated group decreased to $70.9 \pm 4.3 \%$ due to the slight self-degradation of GSNO. However, the cell viability in the APFB group decreased to $53.4 \pm 2.0 \%$ after NIR laser treatments, illustrating the contribution of a single PTT therapeutic effect for killing the tumor cell. Moreover, as the cells were subjected to the combination treatment of PTT/NO with the GAPGB group, the cell viability significantly decreased to $33.1 \pm 5.3 \%$, indicating that the PTT/NO combination displayed a significant cytotoxic effect compared to either NO gas or PTT alone. Furthermore, we confirm the effect of NO gas on cell apoptosis in Figure $5 \mathrm{c}$,d. The results showed that the control, APFB and GAPFB caused $16.0 \pm 3.8 \%, 36.2 \pm 2.4 \%$, and $47.9 \pm 4.0 \%$ of the apoptosis, respectively. As shown in Figure $5 c$, the early stage of apoptosis was mainly induced from the photothermal effect of AuNCs in APFB, which increased about 20\% compared to the control group. The late stage of apoptosis was mainly attributed to the reactive nitrogen species (RNS) produced by highconcentration $\mathrm{NO}$ generated from the GAPFB, causing destructive activity to the tumor cell. The results indicated that the PTT/NO displayed a synergistic effect for killing tumor cells. Moreover, to confirm the synergistic effect of IDO inhibitor with NO gas, we observed the kynurenine (Kyn) release from the Hep55.1c cells. Since the IDO can produce Kyn from the degradation of tryptophan (Trp), the concentration of Kyn could be decreased under the inhibition of IDO. The Kyn ELISA kit was further used to measure the Kyn concentration and calculate the Kyn inhibition rate [29,30] as shown in Figure 5e. The Kyn inhibition rate of the pure 1-methyl-D-tryptophan (1-M-DT), APFBD, GAPFBD, and GAPFBD with NIR laser was measured as $15.0 \pm 3.6 \%, 16.5 \pm 3.1 \%, 30.1 \pm 4.9 \%$, and $63.6 \pm 2.4 \%$, respectively. The APFBD nanoparticle with 1-M-DT showed no obvious difference in Kyn inhibition compared to pure 1-M-DT, indicating that the 1-M-DT conjugated on the nanoparticle can maintain the same biofunction as 1-M-DT alone. However, the APFBD with GSNO loaded (i.e., GAPFBD) can increase the inhibition rate by about $15 \%$ compared to the APFBD, which illustrated the potential role of NO donors in decreasing the activity of IDO. More surprisingly, GAPFBD with NIR laser showed a higher inhibition rate due to the synergistic effect of a 1-M-DT release and the produced NO gas after NIR laser heating. The result demonstrated that the NO gas production accompanied with 1-M-DT release under PTT can significantly increase the Kyn inhibition rate, revealing the great potential effect of using the PTT/NO/IDO nanoplatform.

\subsection{In Vitro DCs Maturation Efficiency of PTT/NO/IDO Synergy}

Dendritic cells (DCs), the most potent antigen-presenting cells of the immune system, can activate naive $T$ cells and induce immune memory responses in cancer [31]. Normally, the expression of $\mathrm{CD} 80^{+}$and $\mathrm{CD} 6^{+}$was used to evaluate the maturation of DCs [32]. To analyze the efficient antitumor immune response induced by PTT/NO/IDO nanoplatform, we investigated the maturation of DCs treated under different conditions of (PTT (APFB + NIR laser), NO (GAPFB), IDO (APFBD), PTT /NO (GAPFB + NIR laser), PTT/IDO (APFBD + NIR laser), NO/IDO (GAPFBD), and PTT/NO/IDO (GAPFBD + NIR laser)) using the flow cytometry in Figure 6 . The expression of $\mathrm{CD} 80^{+} / \mathrm{CD} 86^{+}$of control (DCs) and DCs + tumor with/without NIR laser was measured as shown in Figure S5. As the Hep55.1c was treated with $\mathrm{APFB}$, the expression of $\mathrm{CD} 80^{+} / \mathrm{CD} 86^{+}$was nearly equal to the control group because the APFB contained no drug or without treatments. After being treated with APFBD and GAPFB, it was found to be only $5 \%$ and $8 \%$ higher than APFB, respectively, indicating that the nanoparticle with a single IDO inhibitor or GSNO displayed poor DC maturation. However, the Hep55.1c treated with APFB and NIR laser irradiation presented 1.6-fold higher expression of $\mathrm{CD} 80^{+} / \mathrm{CD}^{+} 6^{+}$than $\mathrm{APFB}$, illustrating that the nanoparticle 
with a single PTT played a crucial role in DC maturation. To evaluate the combination of IDO inhibitor and GSNO with PTT, NIR laser was applied to both groups of APFBD and GAPFB. The $\mathrm{CD}^{2} 0^{+} / \mathrm{CD}^{2} 6^{+}$expression was increased by $10 \%$ (APFBD + Laser) and $13 \%$ (GAPFB + Laser), more than APFB with single PTT, which demonstrated the synergistic effect from the contribution of IDO inhibitor and GSNO. Moreover, the GAPFBD with NIR laser can simultaneously increase the NO production and enhance the release of 1-M-DT, leading to a $20 \%$ increase of the $\mathrm{CD} 80^{+} / \mathrm{CD} 86^{+}$compared to GAPFBD alone. The result confirmed that GAPFBD with the synergistic effects of PTT/NO/IDO can largely promote the maturation of DCs because PTT/NO can induce the tumor-associated antigens (TAAs) accompanied with the inhibition of IDO by 1-M-DT.

(a)

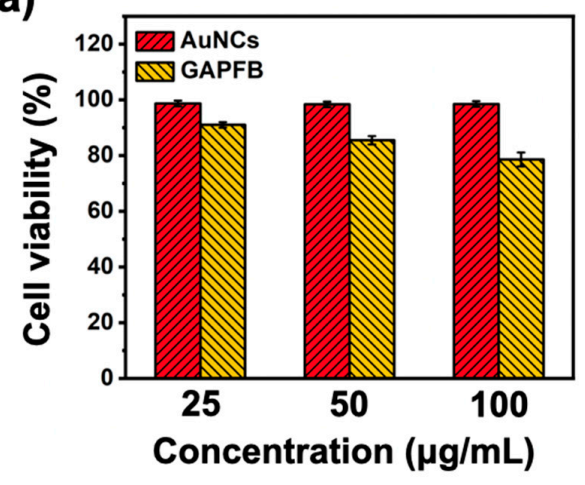

(b)

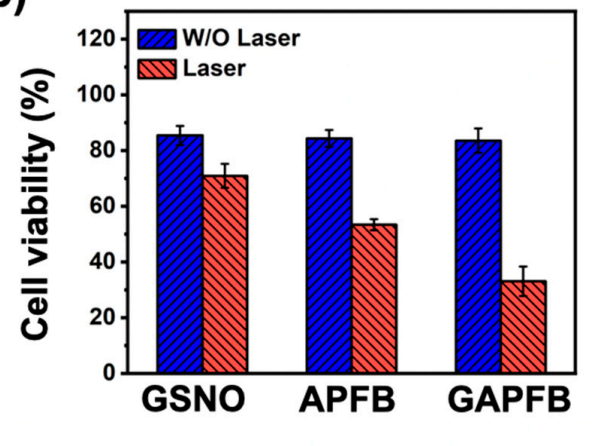

(c)

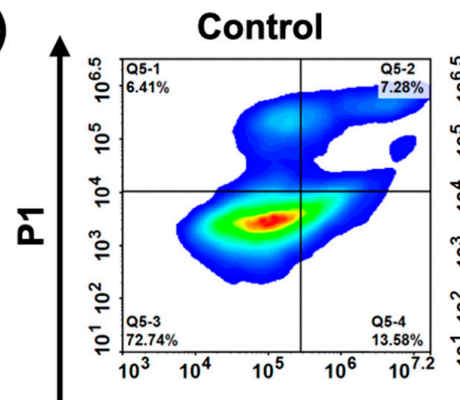

APFB

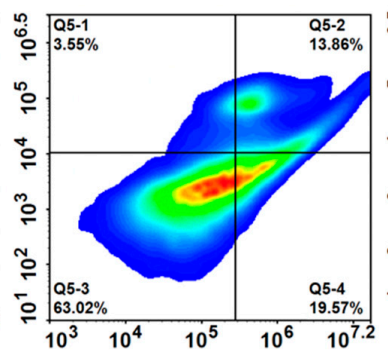

GAPFB

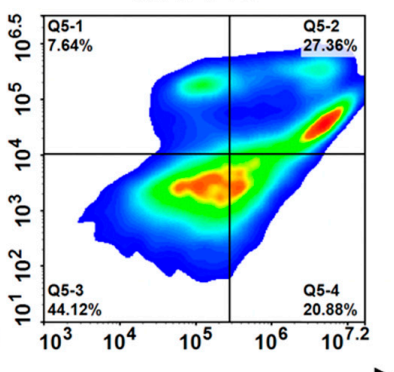

Annexin V

(d)

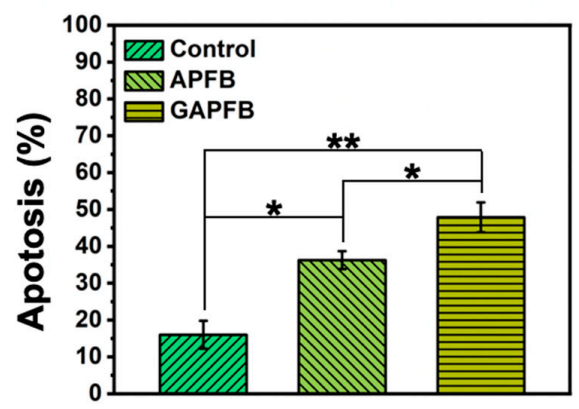

(e)

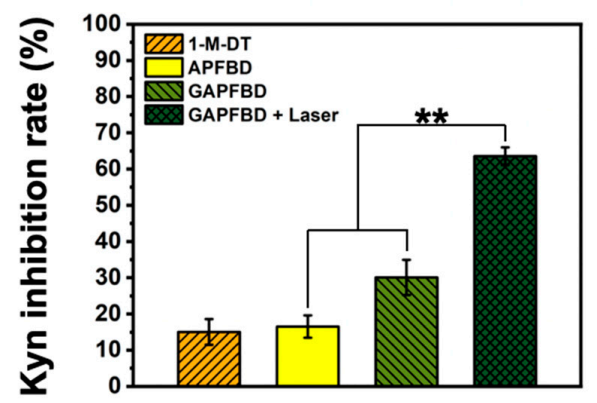

Figure 5. (a) Cytotoxicity assay for AuNCs and GAPFB in Hep55.1c without NIR laser irradiation. (b) In vitro cell viability for GSNO, APFB, and GAPFB in Hep55.1c with/without NIR laser irradiation. (c) Flow cytometry expression of PI and Annexin V for apoptosis. (d) Quantitative results of control, APFB, and GAPFB. (e) Kyn inhibition ratio of 1-M-DT, GSNO-AuNCs-1-M-DT, and GSNO-AuNCs-1M-DT with NIR laser. Data are expressed as mean $\pm \mathrm{SD}, n=3$. Two-tailed Student's test was used. ${ }^{*} p<0.05,{ }^{* *} p<0.01$. 
(a)

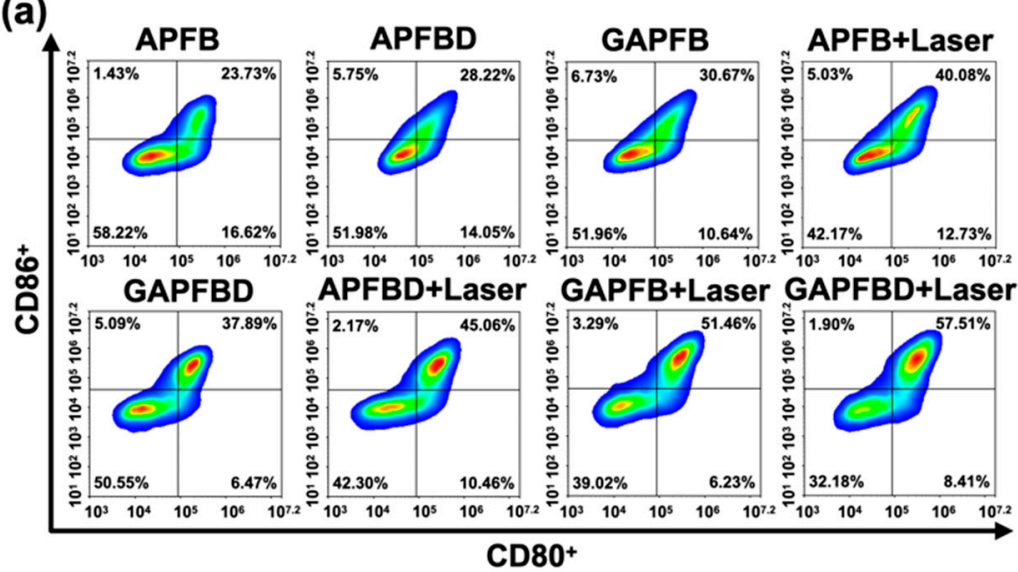

(b)

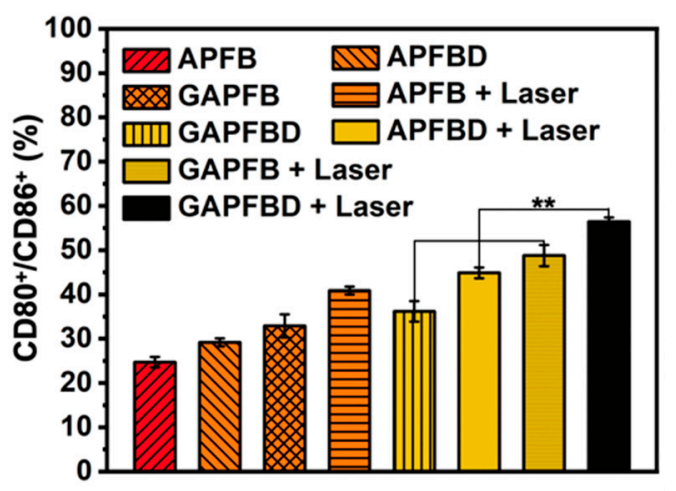

Figure 6. Analysis of immune responses induced by PTT/NO/IDO therapeutic nanoparticle. (a) Flow cytometry expression of $\mathrm{CD} 80^{+}$and $\mathrm{CD}^{2} 6^{+}$on mature DCs surface. (b) Quantitative results. Data are expressed as mean $\pm \mathrm{SD}, n=3$. Two-tailed Student's test was used. ${ }^{* *} p<0.01$.

\section{Materials and Methods}

\subsection{Materials}

Ethylene glycol, silver nitrate $\left(\mathrm{AgNO}_{3}\right), \mathrm{PVP}$ (powder, average $\left.\mathrm{Mw} \sim 29000\right), \mathrm{Na}_{2} \mathrm{~S} \cdot 9 \mathrm{H}_{2} \mathrm{O}$, $\mathrm{HAuCl}_{4} \cdot 3 \mathrm{H}_{2} \mathrm{O}$, sodium chloride, polyacrylic acid (PAA) $(\mathrm{Mw}=1800)$, S-nitrosoglutathione (GSNO, 97\%), iron(II) iron(III) oxide $\left(\mathrm{Fe}_{3} \mathrm{O}_{4}\right)$, Betanin, 1-methyl-D-tryptophan (1-M-DT, 95\%), N-(3-dimethylaminopropyl)-N'-ethylcarbodiimide hydrochloride (EDC, 98\%), Nhydroxysuccinimide (NHS, 98\%), nitric oxide multispecies ELISA Kit (Thermo Fisher Scientific, Waltham, MA, USA), Kynurenine (Kyn) ELISA Kit (FineTest, Wuhan, China), phosphate buffered saline (PBS), CellTiter $96^{\circledR}$ AQueous One Solution Cell Proliferation Assay (MTS reagent) (Promega Co., Madison, WI, USA), Dead Cell Apoptosis Kit with Annexin V Alexa Fluor ${ }^{\mathrm{TM}} 488$ \& propidium iodide (PI) (Invitrogen, St. Louis, MO, USA), Alexa Fluor ${ }^{\mathrm{TM}}$ Plus 750 Phalloidin (Invitrogen, Waltham, MA, USA).

\subsection{Preparation of Gold Nanocages ( $A u N C s$ )}

The procedure of synthesizing AuNCs followed Xia's group publication reported in 2007 [33]. First, the silver nanocage (AgNC) solution and the PVP solution $(9 \mathrm{mM}, 10 \mathrm{~mL})$ were added into the double-necked flask, then $\mathrm{HAuCl}_{4}$ solution $(0.2 \mathrm{mM})$ was titrated to the mixture at a rate of $10-15 \mathrm{~mL} / \mathrm{h}$. To obtain a desirable LSPR peak $(808 \mathrm{~nm})$ of AuNCs, a UV-visible spectrum (Evolution 300, Thermo Fisher Scientific) was used to ensure the stop point of the reaction. Next, sodium chloride $(\mathrm{NaCl})$ was added into the mixture until supersaturation, and the supernatant was collected and centrifuged three times at $11,000 \mathrm{rpm}$ for $10 \mathrm{~min}$. AuNCs were collected in DI water and stored at $4{ }^{\circ} \mathrm{C}$.

\subsection{Synthesis of GSNO-AuNCs-PAA (GAP)}

Synthesis of GSNO-AuNCs-PAA can be divided into two steps. First, the procedure of coating AuNCs with PAA followed Feng's group publication reported in 2019 [34]. The PAA $(25 \%(v / v, 10 \mu \mathrm{L})$ was added to $10 \mathrm{~mL}$ of AuNCs in $\mathrm{NaOH}$ solution $(0.5 \mathrm{M}, 40 \mu \mathrm{L})$, then shaken $(100 \mathrm{rpm})$ at room temperature for $3 \mathrm{~h}$. After the reaction was stopped, the solution was centrifuged three times at 10,000 rpm for $10 \mathrm{~min}$. AuNCs-PAA were collected in pH 6.5 phosphate buffer $(5 \mathrm{~mL})$ and stored at $4{ }^{\circ} \mathrm{C}$. Second, $1 \mathrm{~mL}$ of GSNO $(1 \mathrm{mg} / \mathrm{mL})$ was mixed with $5 \mathrm{~mL}$ of AuNCs-PAA suspension $(5 \mathrm{mg} / \mathrm{mL}$ in $\mathrm{pH}=6.5$ phosphate buffer) and shaken $(100 \mathrm{rpm})$ at $4{ }^{\circ} \mathrm{C}$ in the dark overnight. After the reaction stopped, the solution was centrifuged three times at 10,000 rpm for $10 \mathrm{~min}$. GSNO-AuNCs-PAA was re-dissolved in a phosphate buffer $(\mathrm{pH} 7.4,1 \mathrm{~mL})$ and stored at $4{ }^{\circ} \mathrm{C}$. 


\subsection{Synthesis of GSNO-AuNCs-PAA-Fe $\mathrm{O}_{4}$-Betanin-1-M-DT (GAPFBD)}

Synthesis of GSNO-AuNCs-PAA- $\mathrm{Fe}_{3} \mathrm{O}_{4}$-betanin-1-M-DT (GAPFBD) was divided into two steps, which were the synthesis of GAPFB and grafted 1-methyl-D-tryptophan (1M-DT) onto the surface of GAPFB. First, $2 \mathrm{~mL}$ of iron oxide $(1 \mathrm{mg} / \mathrm{mL})$ and $1 \mathrm{~mL}$ of GSNO-AuNCs-PAA suspension $(1 \mathrm{mg} / \mathrm{mL})$ were mixed and shaken overnight under $4{ }^{\circ} \mathrm{C}$ in the dark. Then, the ungrafted iron oxide was removed using a micro-separation magnetic holder and GAPF was collected. Second, $2 \mathrm{~mL}$ of betanin $(10 \mathrm{mg} / \mathrm{mL})$ and $1 \mathrm{~mL}$ of GAPF suspension were mixed and shaken overnight under $4{ }^{\circ} \mathrm{C}$ in the dark. The ungrafted betanin was removed using a micro-separation magnetic holder. GAPFB was re-dissolved in $\mathrm{pH} 6.0$ phosphate buffer and stored under $4{ }^{\circ} \mathrm{C}$. Next, The EDC $(1.6 \mathrm{mM})$ was added to the GAPFB solution and shaken in the dark for $1 \mathrm{~h}$, then NHS (4 mM) and 1-M-DT were added $(1 \mathrm{mg} / \mathrm{mL})$ into the mixture and shaken for $4 \mathrm{~h}$ in the dark. Next, the ungrafted 1-MDT was removed using the micro-separation magnetic holder. GAPFBD was re-dissolved in a $\mathrm{pH} 6.0$ phosphate buffer and stored under $4{ }^{\circ} \mathrm{C}$.

\subsection{Characterization of GAPFBD}

The morphology of AuNCs and GAPFBD were observed using a scanning electron microscope (SEM) and transmission electron microscope (TEM). The zeta potential and particle size of AuNCs, GAP, GAPF, GAPFB, and GAPFBD were measured by electrophoretic light scattering and dynamic light scattering (ELS and DLS; Delsa Nano C particle analyzer, Beckman Coulter, Brea, CA, USA).

\subsection{Photothermic Effect and Stability of GAPFBD}

The GAPFBD solution (AuNCs, $50 \mu \mathrm{g} / \mathrm{mL}$ ) was irradiated under 808-nm laser (LSPPS-FA, Lasever, Ningbo, China) $\left(0.5 \mathrm{~W} / \mathrm{cm}^{2}\right)$, and the heating curve plot was recorded by the temperature value of every 30 seconds for a period of $15 \mathrm{~min}$. The GAPFBD solution (AuNCs, $50 \mu \mathrm{g} / \mathrm{mL}$ ) was irradiated by $808-\mathrm{nm}$ laser $\left(0.5 \mathrm{~W} / \mathrm{cm}^{2}\right)$ for $15 \mathrm{~min}$, then, the laser turned off to cool down to room temperature. This cycle was repeated three times.

\subsection{Drug Loading Ability}

The suspension of GAP was collected to measure the absorbance at $335 \mathrm{~nm}$ by ELISA reader (DV990BV4, GDV, Milan, Italy). The S-nitroso group in the AuNCs was retrospectively calculated using the standard curve [15], and the encapsulation ratio (ER\%) was estimated by the following formula [35].

$E R \%=[($ the original amount of sample solution-amount of supernatant after centrifugation)/original amount of sample solution] $\times 100 \%$.

\subsection{NO Production of GAPFB}

GSNO powder was dissolved in deionized water $(50 \mu \mathrm{g} / \mathrm{mL})$ and placed at $4{ }^{\circ} \mathrm{C}$ for three days before the experiment of NO production. GSNO and GAPFB $(50 \mu \mathrm{g} / \mathrm{mL})$ were irradiated by the 808-nm laser (LSP-PS-FA, Lasever, Ningbo, China) $\left(0.5 \mathrm{~W} / \mathrm{cm}^{2}, 10 \mathrm{~min}\right)$, and subsequently, the supernatants were collected for NO analysis. During the experiment, the laser with a square spot size of $4 \mathrm{~mm}^{2}$ was used to irradiate the $1 \mathrm{~mL}$ of the solution containing the collected supernatants. After the irradiation at $0.5 \mathrm{~W} / \mathrm{cm}^{2}$ for $10 \mathrm{~min}$, the irradiated fluid and the biological solution without laser were measured by the Nitric Oxide Assay Kit. The absorbance values at $540 \mathrm{~nm}$ were used to estimate the release amount based on the standard curve (Figure S4).

\subsection{GSNO Release of GAPFB}

GAPFB $(50 \mu \mathrm{g} / \mathrm{mL})$ was placed in three $\mathrm{pH}$ values of phosphate buffer solutions (7.4, $6.5,5.0$, respectively) and shaken at $37^{\circ} \mathrm{C}$. The supernatant was collected at $1,2,4,8,12,24$, 48 , and $72 \mathrm{~h}$. The concentration of GSNO was measured by Microplate Spectrophotometer (BioTek, Agilent, Santa Clara, CA, USA) at the absorbance of $335 \mathrm{~nm}$. 


\subsection{1-M-DT Release of GAPFBD}

GAPFBD $(50 \mu \mathrm{g} / \mathrm{mL})$ was placed in three $\mathrm{pH}$ values of phosphate buffer solutions (7.4, 6.5, and 5.0, respectively) and shaken at $37^{\circ} \mathrm{C}$. GAPFBD under $\mathrm{pH}$ value of 6.5 and 7.4 were irradiated by the 808-nm laser (LSP-PS-FA, Lasever, Ningbo, China) $\left(0.5 \mathrm{~W} / \mathrm{cm}^{2}\right.$, $10 \mathrm{~min}$ ) after $24 \mathrm{~h}$. The supernatant was collected at 1, 2, 4, 8, 12, 24, 48, and $72 \mathrm{~h}$. The concentration of 1-M-DT was measured by microplate spectrophotometer (BioTek, Agilent, Santa Clara, CA, USA) at the absorbance of $223 \mathrm{~nm}$.

\subsection{Cell Culture}

Hep55.1c (RRID: CVCL_5766) mouse liver cancer cell line was provided by China Medical University in Taiwan. Hep55.1c was cultured with DMEM medium supplemented with $10 \%$ fetal bovine serum (FBS) and $1 \%$ penicillin-streptomycin in a $37{ }^{\circ} \mathrm{C}, 5 \% \mathrm{CO}_{2}$ incubator. Trypsin was applied on Hep55.1c for subculture. Bone marrow cells which were extracted from thigh bones of 6-8-week-old C57BL/6 WT mice were induced to differentiate to dendritic cells (DCs) in 5 to 6 days culture in RPMI 1640 medium supplemented with $10 \%$ FBS, $1 \%$ sodium pyruvate, $1 \%$ nonessential amino acids, $1 \%$ penicillin/streptomycin, GM-CSF $(20 \mathrm{ng} / \mathrm{mL})$, and IL-4 $(10 \mathrm{ng} / \mathrm{mL})$. The cells were cultured in a complete medium at $37^{\circ} \mathrm{C}$ in a humidified atmosphere with $5 \%$ carbon dioxide in the air.

\subsection{Cytotoxicity Assay of Hep55.1c Treated with Nanoparticle}

The cell viability was tested by MTS Assay Kit. The cell suspension was added to a 96-well plate with $10^{4}$ cells/well and placed in an incubator $\left(37^{\circ} \mathrm{C}, 5 \% \mathrm{CO}_{2}\right)$ for $24 \mathrm{~h}$. Next, the different concentrations of the AuNCs and GAPFB (AuNCs, 25, 50, and $100 \mu \mathrm{g} / \mathrm{mL}$ ) were added and incubated for $24 \mathrm{~h}$. A medium containing 10\% MTS reagent was added to each well and incubated for $2 \mathrm{~h}$, then the optical absorbance was quantified at $490 \mathrm{~nm}$ using a microplate spectrophotometer (BioTek, Agilent, Santa Clara, CA, USA).

\subsection{Cell Uptake}

The cells were suspended at $10^{5}$ cells/well into a 24-well plate and placed in an incubator $\left(37^{\circ} \mathrm{C}, 5 \% \mathrm{CO}_{2}\right)$ for $24 \mathrm{~h}$. The GAPFBD $(50 \mu \mathrm{g} / \mathrm{mL})$ was added and incubated for $1,4,12$, and $24 \mathrm{~h}$. The cell suspension was centrifuged ( $1500 \mathrm{rpm}, 5 \mathrm{~min}$ ) three times for washing, then cell uptake was observed by flow cytometry. For fluorescent microscope, the cell suspension with $10^{5}$ cells/well and coverslip were put into a 24-well plate, then placed in an incubator for $24 \mathrm{~h}$. The nanoparticle was mixed with culture medium and added into each well for 1, 4, 12, and $24 \mathrm{~h}$. The cells were fixed with 3.7\% paraformaldehyde in PBS for $30 \mathrm{~min}$ and reacted with $0.25 \%$ Triton $\mathrm{x}-100$ in PBS for $15 \mathrm{~min}$. Next, the cells were blocked with $2 \%$ BSA in PBS for $1 \mathrm{~h}$, and then the cytoskeleton was stained with Alexa Fluor ${ }^{\circledR}$ 750 Phalloidin ( 5 unit $/ \mathrm{mL}$ ) for $1 \mathrm{~h}$. Finally, the cells were mounted on a clean glass slide by DAPI-containing mounting medium (Sigma, Saint Louis, MO, USA). The fluorescence images were observed by confocal microscopy (D-eclipse C1; Eclipse, TE2000-U, Nikon, Tokyo, Japan).

\subsection{NO/Photothermal Treatment of Hep55.1c Cell}

The cell suspension was added with $10^{5}$ cells/well to a 24-well plate and placed in an incubator for $24 \mathrm{~h}$. Next, the nanoparticles of each group (GSNO, APFB, and GAPFB) were added to each well and incubated for $24 \mathrm{~h}$. Hep55.1c cells were then treated with an 808-nm laser (LSP-PS-FA, Lasever, Ningbo, China) $\left(0.5 \mathrm{~W} / \mathrm{cm}^{2}, 10 \mathrm{~min}\right)$ or no treatment as a control. After treatment, the cells were cultured for another $24 \mathrm{~h}$. The medium containing MTS reagent $(10 \%)$ was added to each well and incubated for $2 \mathrm{~h}$, then the optical absorbance was quantified at $490 \mathrm{~nm}$ using a microplate spectrophotometer (BioTek, Agilent, Santa Clara, CA, USA). 


\subsection{Apoptosis Analysis of GAPFB}

Hep55.1c cell suspension with a concentration of $10^{5}$ cells/well was added to a 24-well plate and placed in the incubator for $24 \mathrm{~h}$. Next, the nanoparticles of each group (APFB and GAPFB) were added to each well and incubated for $24 \mathrm{~h}$. Hep55.1c cells were then treated with an 808-nm laser (LSP-PS-FA, Lasever, Ningbo, China) $\left(0.5 \mathrm{~W} / \mathrm{cm}^{2}, 10 \mathrm{~min}\right)$. After treatment, the cells were cultured for another $24 \mathrm{~h}$. The cells were removed by $0.25 \%$ trypsin with $0.02 \%$ EDTA. The cell suspension was centrifuged at $1500 \mathrm{rpm}$ for $5 \mathrm{~min}$ and re-dissolved in $1 \times$ annexin-binding buffer. Next, Alexa Fluor 488 annexin V and PI working solution cell apoptosis reagents were added to react for $15 \mathrm{~min}$ at room temperature. Finally, $1 \times$ annexin-binding buffer was added to the mix, and apoptosis analysis was performed using flow cytometry (Novocyte ${ }^{\circledR}$, ACEA biosciences, San Diego, CA, USA).

\subsection{Kyn Inhibition}

A cell suspension with $10^{5}$ cells/well was added to a 24-well plate, placed in a box, and incubated at $37^{\circ} \mathrm{C}$ and $5 \% \mathrm{CO}_{2}$ for $24 \mathrm{~h}$ to stabilize the cell growth. Next, the nanoparticles of each group (1-M-DT, APFBD, and GAPFBD) were added to each well and incubated at $37^{\circ} \mathrm{C}$ and $5 \% \mathrm{CO}_{2}$ for $48 \mathrm{~h} \mathrm{[36].} \mathrm{After} \mathrm{that,} \mathrm{the} \mathrm{Hep55.1c} \mathrm{cells} \mathrm{were} \mathrm{treated} \mathrm{with} \mathrm{the} \mathrm{808-nm}$ laser (LSP-PS-FA, Lasever, Ningbo, China) $\left(0.5 \mathrm{~W} / \mathrm{cm}^{2}, 10 \mathrm{~min}\right)$ or without any treatment. After the treatment, the cells were cultured for another $24 \mathrm{~h}$. The supernatant was collected as sample reagents after centrifuging cell culture supernatant for $20 \mathrm{~min}$ at $1000 \times g$ and running the assay procedure by Kyn ELISA Kit. The O.D. absorbance was read at $450 \mathrm{~nm}$ in the microplate spectrophotometer (BioTek, Agilent, Santa Clara, CA, USA) to measure the inhibition rate.

\subsection{Analysis of Mature DCs Surface-Marker Expression}

The transwell system was used for co-culturing Hep55.1c cells and dendritic cells (DCs), and the DCs were cultured according to the study of Alka et al. [37]. On the fifth day, Hep55.1c cell suspension with $10^{5}$ cells/well was added to the upper chamber of the transwell and placed in the incubator for $24 \mathrm{~h}$. Next, the nanoparticles of each group (APFB, GAPFB, and GAPFBD) were added to the upper chamber of the transwell and incubated for $24 \mathrm{~h}$. Hep55.1c cells were then treated with an 808-nm laser (LSP-PS-FA, Lasever, Ningbo, China) $\left(0.5 \mathrm{~W} / \mathrm{cm}^{2}, 10 \mathrm{~min}\right)$, and the cells were cultured for another $4 \mathrm{~h}$. After culturing the cells extracted from the mouse thigh bone for six days, the non-adherent primary bone marrow dendritic cells (BMDC) were collected by gently pipetting the culture medium. The BMDC cell suspension with $2 \times 10^{5}$ cells/well was added to the lower chamber of the transwell and placed in the incubator for $20 \mathrm{~h}$. To analyze the expression of cell surface markers, BMDC was collected to centrifuge and wash with PBS at $250 \times g$ for 8 min three times. The BMDC were stained with anti-CD11c-FITC (RUO), anti-CD80-PE (16-10A1), and anti-CD86-PE (GL1) at $4{ }^{\circ} \mathrm{C}$ in the dark for $30 \mathrm{~min}$. The DC phenotype was evaluated by flow cytometry, and the result was expressed by the distribution of fluorescence intensity.

\section{Conclusions}

In this study, we have successfully developed a dual-sensitive GAPFBD nanoparticle as a single nano-platform to achieve combination therapy of photothermal therapy (PTT), NO gas therapy, and IDO immunotherapy. The results proved this dual-sensitive nanoparticle can co-deliver and precisely release GSNO and 1-M-DT through the control by 808-nm laser under a certain $\mathrm{pH}$ environment, leading to tumor destruction. The synergistic effect has demonstrated the efficiently anti-tumor therapeutic effects and the great potential of producing the tumor-associated antigens (TAAs) using the GAPFBD to stimulate the maturation of dendritic cells (DCs), leading to long-term immunity. Further, the excellent achievement clarified in this study makes it a promising choice for in vivo studies and clinical applications in combination cancer therapies. 
Supplementary Materials: The following are available online at https:/ / www.mdpi.com/article/ 10.3390/ph15020138/s1, Figure S1: Elemental analysis. (a) GAP and (b) GAPFBD, Figure S2: Standard curve of (a) GSNO and (b) 1-M-DT, Figure S3: (a) GSNO and (b) 1-M-DT stability of GAPFBD under storge condition of $\mathrm{pH}=7.4$ and $\mathrm{pH}=6.0$, Figure S4: Standard curve of nitrite concentration, Figure S5: Analysis of immune responses induced by PTT/NO/IDO therapeutic nanoparticle. (a) Flow cytometry expression of CD80+ and CD86+ on mature DCs surface. (b) Quantitative results, Table S1: Element analysis of the GAPFBD.

Author Contributions: Conceptualization, H.-W.C. and H.-Y.T.; methodology, C.-C.K.; software, H.-Y.T. and C.-C.K.; validation, H.-Y.T. and C.-C.K.; formal analysis, H.-W.C., H.-Y.T. and C.-C.K.; investigation, H.-Y.T. and C.-C.K.; resources, S.-Y.C.; data curation, H.-Y.T.; writing-original draft preparation, H.-Y.T.; writing-review and editing, H.-W.C. and S.-Y.C.; visualization, H.-W.C. and H.-Y.T.; supervision, S.-Y.C.; project administration, S.-Y.C.; funding acquisition, S.-Y.C. All authors have read and agreed to the published version of the manuscript.

Funding: The authors express thanks for the research grants of MOST 108-2221-E-009-078-MY3 and MOST 109-2221-E-009-017-MY3 from the Ministry of Science and Technology in Taiwan.

Institutional Review Board Statement: Not applicable.

Informed Consent Statement: Not applicable.

Data Availability Statement: The data presented in this study are available on request from the corresponding author.

Conflicts of Interest: The authors declare no conflict of interest.

\section{References}

1. Qian, S.; Zhang, M.; Chen, Q.; He, Y.; Wang, W.; Wang, Z. IDO as a drug target for cancer immunotherapy: Recent developments in IDO inhibitors discovery. RSC Adv. 2016, 6, 7575-7581. [CrossRef]

2. June, C.H.; O'Connor, R.S.; Kawalekar, O.U.; Ghassemi, S.; Milone, M.C. CAR T cell immunotherapy for human cancer. Science 2018, 359, 1361-1365. [CrossRef]

3. Pardoll, D.M. The blockade of immune checkpoints in cancer immunotherapy. Nat. Rev. Cancer 2012, 12, 252-264. [CrossRef]

4. Fallarino, F.; Grohmann, U.; Hwang, K.W.; Orabona, C.; Vacca, C.; Bianchi, R.; Belladonna, M.L.; Fioretti, M.C.; Alegre, M.-L.; Puccetti, P. Modulation of tryptophan catabolism by regulatory T cells. Nat. Immunol. 2003, 4, 1206-1212. [CrossRef]

5. Jans, H.; Jans, K.; Lagae, L.; Borghs, G.; Maes, G.; Huo, Q. Poly(acrylic acid)-stabilized colloidal gold nanoparticles: Synthesis and properties. Nanotechnology 2010, 21, 455702. [CrossRef]

6. Chen, Y.; Xia, R.; Huang, Y.; Zhao, W.; Li, J.; Zhang, X.; Wang, P.; Venkataramanan, R.; Fan, J.; Xie, W.; et al. An immunostimulatory dual-functional nanocarrier that improves cancer immunochemotherapy. Nat. Commun. 2016, 7, 13443. [CrossRef]

7. Xing, L.; Gong, J.-H.; Wang, Y.; Zhu, Y.; Huang, Z.-J.; Zhao, J.; Li, F.; Wang, J.-H.; Wen, H.; Jiang, H.-L. Hypoxia alleviationtriggered enhanced photodynamic therapy in combination with IDO inhibitor for preferable cancer therapy. Biomaterials 2019, 206, 170-182. [CrossRef]

8. Vong, L.; Nagasaki, Y. Nitric Oxide Nano-Delivery Systems for Cancer Therapeutics: Advances and Challenges. Antioxidants 2020, 9, 791. [CrossRef]

9. Choudhari, S.K.; Chaudhary, M.; Bagde, S.; Gadbail, A.R.; Joshi, V. Nitric oxide and cancer: A review. World J. Surg. Oncol. 2013, 11, 118. [CrossRef]

10. Rapozzi, V.; Della Pietra, E.; Bonavida, B. Dual roles of nitric oxide in the regulation of tumor cell response and resistance to photodynamic therapy. Redox Biol. 2015, 6, 311-317. [CrossRef]

11. Goedegebuure, R.S.A.; De Klerk, L.K.; Bass, A.J.; Derks, S.; Thijssen, V.L.J.L. Combining Radiotherapy With Anti-angiogenic Therapy and Immunotherapy; A Therapeutic Triad for Cancer? Front. Immunol. 2019, 9, 3107. [CrossRef]

12. Thomas, S.; Mohr, D.; Stocker, R. Nitric oxide inhibits indoleamine 2,3-dioxygenase activity in interferon-gamma primed mononuclear phagocytes. J. Biol. Chem. 1994, 269, 14457-14464. [CrossRef]

13. Alimoradi, H.; Greish, K.; Gamble, A.B.; Giles, G.I. Controlled Delivery of Nitric Oxide for Cancer Therapy. Pharm. Nanotechnol. 2019, 7, 279-303. [CrossRef]

14. Xu, W.; Liu, L.Z.; Loizidou, M.; Ahmed, M.; Charles, I.G. The role of nitric oxide in cancer. Cell Res. 2002, 12, 311-320. [CrossRef]

15. Broniowska, K.A.; Diers, A.R.; Hogg, N. S-Nitrosoglutathione. Biochim. Biophys. Acta (BBA)—Gen. Subj. 2013, 1830, 3173-3181. [CrossRef]

16. Yang, Y.; Huang, Z.; Li, L.-L. Advanced nitric oxide donors: Chemical structure of NO drugs, NO nanomedicines and biomedical applications. Nanoscale 2020, 13, 444-459. [CrossRef]

17. Rapozzi, V.; Della Pietra, E.; Zorzet, S.; Zacchigna, M.; Bonavida, B.; Xodo, L. Nitric oxide-mediated activity in anti-cancer photodynamic therapy. Nitric Oxide 2013, 30, 26-35. [CrossRef] 
18. Wu, W.; Chen, M.; Luo, T.; Fan, Y.; Zhang, J.; Zhang, Y.; Zhang, Q.; Sapin-Minet, A.; Gaucher, C.; Xia, X. ROS and GSH-responsive S-nitrosoglutathione functionalized polymeric nanoparticles to overcome multidrug resistance in cancer. Acta Biomater. 2020, 103, 259-271. [CrossRef]

19. Zhang, X.; Tian, G.; Yin, W.; Wang, L.; Zheng, X.; Yan, L.; Li, J.; Su, H.; Chen, C.; Gu, Z.; et al. Controllable Generation of Nitric Oxide by Near-Infrared-Sensitized Upconversion Nanoparticles for Tumor Therapy. Adv. Funct. Mater. 2015, 25, 3049-3056. [CrossRef]

20. Skrabalak, S.E.; Chen, J.; Au, L.; Lu, X.; Li, X.; Xia, Y. Gold Nanocages for Biomedical Applications. Adv. Mater. 2007, 19, 3177-3184. [CrossRef]

21. Nejati, K.; Dadashpour, M.; Gharibi, T.; Mellatyar, H.; Akbarzadeh, A. Biomedical Applications of Functionalized Gold Nanoparticles: A Review. J. Clust. Sci. 2021, 33, 1-16. [CrossRef]

22. Huang, X.; Xu, F.; Hou, H.; Hou, J.; Wang, Y.; Zhou, S. Stimuli-responsive nitric oxide generator for light-triggered synergistic cancer photothermal/gas therapy. Nano Res. 2019, 12, 1361-1370. [CrossRef]

23. Nurkeeva, Z.S.; Khutoryanskiy, V.V.; Mun, G.A.; Sherbakova, M.V.; Ivaschenko, A.T.; Aitkhozhina, N.A. Polycomplexes of poly(acrylic acid) with streptomycin sulfate and their antibacterial activity. Eur. J. Pharm. Biopharm. 2004, 57, 245-249. [CrossRef]

24. Esatbeyoglu, T.; Wagner, A.E.; Schiniatbeyo, V.B.; Rimbach, G. Betanin-A food colorant with biological activity. Mol. Nutr. Food Res. 2014, 59, 36-47. [CrossRef]

25. Chen, J.; Glaus, C.; Laforest, R.; Zhang, Q.; Yang, M.; Gidding, M.; Welch, M.J.; Xia, Y. Gold Nanocages as Photothermal Transducers for Cancer Treatment. Small 2010, 6, 811-817. [CrossRef]

26. Lin, J.-T.; Chiang, Y.-S.; Lin, G.-H.; Lee, H.; Liu, H.-W. In Vitro Photothermal Destruction of Cancer Cells Using Gold Nanorods and Pulsed-Train Near-Infrared Laser. J. Nanomater. 2012, 2012, 861385. [CrossRef]

27. Yuan, A.; Wu, J.; Tang, X.; Zhao, L.; Xu, F.; Hu, Y. Application of Near-Infrared Dyes for Tumor Imaging, Photothermal, and Photodynamic Therapies. J. Pharm. Sci. 2013, 102, 6-28. [CrossRef]

28. Fan, J.; He, N.; He, Q.; Liu, Y.; Ma, Y.; Fu, X.; Liu, Y.; Huang, P.; Chen, X. A novel self-assembled sandwich nanomedicine for NIR-responsive release of NO. Nanoscale 2015, 7, 20055-20062. [CrossRef]

29. Hou, D.-Y.; Muller, A.; Sharma, M.D.; DuHadaway, J.; Banerjee, T.; Johnson, M.; Mellor, A.L.; Prendergast, G.C.; Munn, D. Inhibition of Indoleamine 2,3-Dioxygenase in Dendritic Cells by Stereoisomers of 1-Methyl-Tryptophan Correlates with Antitumor Responses. Cancer Res. 2007, 67, 792-801. [CrossRef]

30. Liu, X.; Shin, N.; Koblish, H.K.; Yang, G.; Wang, Q.; Wang, K.; Leffet, L.; Hansbury, M.J.; Thomas, B.; Rupar, M.; et al. Selective inhibition of IDO1 effectively regulates mediators of antitumor immunity. Blood 2010, 115, 3520-3530. [CrossRef]

31. Wculek, S.K.; Cueto, F.J.; Mujal, A.M.; Melero, I.; Krummel, M.F.; Sancho, D. Dendritic cells in cancer immunology and immunotherapy. Nat. Rev. Immunol. 2020, 20, 7-24. [CrossRef] [PubMed]

32. Dilioglou, S.; Cruse, J.M.; Lewis, R.E. Function of CD80 and CD86 on monocyte- and stem cell-derived dendritic cells. Exp. Mol. Pathol. 2003, 75, 217-227. [CrossRef]

33. Skrabalak, S.E.; Au, L.; Li, X.; Xia, Y. Facile synthesis of Ag nanocubes and Au nanocages. Nat. Protoc. 2007, 2, 2182-2190. [CrossRef] [PubMed]

34. Feng, Y.; Cheng, Y.; Chang, Y.; Jian, H.; Zheng, R.; Wu, X.; Xu, K.; Wang, L.; Ma, X.; Li, X.; et al. Time-staggered delivery of erlotinib and doxorubicin by gold nanocages with two smart polymers for reprogrammable release and synergistic with photothermal therapy. Biomaterials 2019, 217, 119327. [CrossRef]

35. Chen, L.-F.; Chen, L.-C.; Chen, C. The Manufacture and Effectiveness Evaluation of Liposome Incorporated with Silk Protein. J. Agric. Forestry. 2015, 64, 1-10.

36. Zhu, Y.; Yang, Z.; Dong, Z.; Gong, Y.; Hao, Y.; Tian, L.; Yang, X.; Liu, Z.; Feng, L. CaCO 3 -Assisted Preparation of pH-Responsive Immune-Modulating Nanoparticles for Augmented Chemo-Immunotherapy. Nano-Micro Lett. 2020, 13, 29. [CrossRef]

37. Madaan, A.; Verma, R.; Singh, A.T.; Jain, S.K.; Jaggi, M. A stepwise procedure for isolation of murine bone marrow and generation of dendritic cells. J. Biol. Methods 2014, 1, e1. [CrossRef] 